\title{
Identical tricuspid ring sizing in simultaneous functional tricuspid and mitral valve repair: A simple and effective strategy
}

Lynn C. Huffman, MD, Jennifer S. Nelson, MD, April N. Lehman, BS, Marguerite C. Krajacic, RN, BSN, and Steven F. Bolling, MD

\begin{abstract}
Objective: Mitral valve repair for functional mitral regurgitation is common. Concomitant tricuspid valve repair for associated functional tricuspid regurgitation has gained favor. Controversy exists regarding annuloplasty sizing for tricuspid valve repair.
\end{abstract}

Methods: Patients with heart failure having functional mitral regurgitation at the University of Michigan and undergoing mitral valve repair and tricuspid valve repair using identical sized annuloplasty rings between April 2007 and January 2012 were identified. Demographic and clinical records were retrospectively reviewed. Institutional review board approval was obtained for this study.

\begin{abstract}
Results: Fifty-three patients met inclusion criteria. Mean age was $65 \pm 1.7$ years. Preoperative New York Heart Association class was III or IV in $81 \%$ (43) and mean left ventricular ejection fraction was $33 \% \pm 2.2 \%$. All patients had moderate or greater mitral regurgitation preoperatively and moderate or severe tricuspid regurgitation or a preoperative tricuspid annulus diameter greater than $40 \mathrm{~mm}$. There was no 30-day mortality. Mean immediate postoperative tricuspid valve gradient was $1.75 \pm 0.12 \mathrm{~mm} \mathrm{Hg}$ and was $2.3 \pm 0.19 \mathrm{~mm} \mathrm{Hg}$ at 4 weeks. Four weeks postoperatively $88 \%$ (42/48) of patients had tricuspid regurgitation considered to be mild or less. There was no significant decline in right ventricular function by echocardiography over this time period.

Conclusions: Functional tricuspid regurgitation can be repaired using an undersized rigid annuloplasty ring. Our data suggest that an identical sizing strategy can be used for tricuspid valve repair, as was used for mitral valve repair, without development of tricuspid stenosis or negative effect on right ventricular function. This method seems to prevent recurrence of significant tricuspid regurgitation. The technique we describe provides effective and reproducible results. (J Thorac Cardiovasc Surg 2014;147:611-4)
\end{abstract}

Functional tricuspid regurgitation (TR) is an important clinical condition for which surgical repair is being increasingly applied. ${ }^{1,2}$ An estimated 1.6 million patients in the United States have moderate or greater TR. ${ }^{3}$ Functional TR is usually a secondary result of left-sided heart failure. ${ }^{4}$ Typically associated with myocardial or valvular dysfunction, right ventricular (RV) enlargement and asymmetric tricuspid annular dilation lead to TR. Patients with untreated TR can have significant clinical symptoms including fatigue, decreased exercise tolerance, edema, and ascites. ${ }^{1}$

TR has been shown to increase mortality independent of left ventricular ejection fraction, RV size, and RV function. ${ }^{5}$ Of special interest is the development of significant TR years after mitral valve (MV) surgery. A growing body of literature supports the notion that "benign neglect" of TR

\footnotetext{
From the University of Michigan, Ann Arbor, Mich.

Disclosures: Authors have nothing to disclose with regard to commercial support. Received for publication May 15, 2011; revisions received Aug 28, 2012; accepted for publication Jan 14, 2013; available ahead of print March 13, 2013.

Address for reprints: Jennifer S. Nelson, MD, University of Michigan, Cardiac Surgery, 5144 CVC, 1500 E Medical Center Dr, SPC 5864, Ann Arbor, MI 48109 (E-mail: jensnels@umich.edu).

$0022-5223 / \$ 36.00$

Copyright (C) 2014 by The American Association for Thoracic Surgery http://dx.doi.org/10.1016/j.jtcvs.2013.01.027
}

at the time of MV surgery (especially in the presence of tricuspid annular dilation) can no longer be considered acceptable. $^{2,5}$

Additionally, reoperations for recurrent TR are associated with high surgical risk (up to $37 \%$ in-hospital mortality). ${ }^{6,7}$ Because of this higher risk, more aggressive treatment of TR at the time of initial surgery may be prudent. This is especially important inasmuch as TR does not reliably resolve, and frequently progressively worsens, even after successful MV surgery. ${ }^{6,8,9}$

If present at the time of MV surgery, functional TR can usually be treated with ring annuloplasty. ${ }^{8}$ Successful tricuspid valve (TV) repair results in a significant improvement in recurrent TR, RV function, event-free survival, and functional outcome. ${ }^{2,7}$ The American College of Cardiology/American Heart Association 2006 Practice Guidelines for the surgical management of patients with TR give a class I indication for TV repair in any patient with severe TR undergoing MV surgery. ${ }^{10}$ Current European Society of Cardiology 2007 guidelines recommend (class IIa) tricuspid repair for moderate TR with a dilated $(>40 \mathrm{~mm})$ annulus in a patient undergoing left-sided surgery. ${ }^{11}$

Significant advances have been made in disease-specific repair strategies for mitral regurgitation, but less is known 


$$
\begin{aligned}
& \text { Abbreviations and Acronyms } \\
& \mathrm{CI}=\text { confidence interval } \\
& \mathrm{MV}=\text { mitral valve } \\
& \mathrm{RV}=\text { right ventricular } \\
& \mathrm{TR}=\text { tricuspid regurgitation } \\
& \mathrm{TS}=\text { tricuspid stenosis } \\
& \mathrm{TV}=\text { tricuspid valve }
\end{aligned}
$$

about similar repair strategies for concomitant TR. Many would agree that rigid ring TV annuloplasty offers a better long-term solution than a nonring approach. ${ }^{8,12,13}$ In a study of 790 patients undergoing TV repair via 4 different methods, McCarthy and associates ${ }^{8}$ found that recurrent TR became more severe faster and was more prevalent after a De Vega compared with a ring annuloplasty. Others have corroborated the finding of late recurrence of significant TR after De Vega, including a prospective randomized trial by Rivera and associates ${ }^{12}$ comparing De Vega with the Carpentier-Edwards ring.

Controversy exists regarding size selection for TV annuloplasty. ${ }^{8,13-15}$ Methods of sizing have varied. Some have warned against undersizing the TV annuloplasty to avoid a theoretical risk of tricuspid stenosis (TS) or RV failure from loss of "pop-off," whereas others have suggested complex methods such as using a ratio of 2.43:1 between the anteroposterior and septal segments as a guide. ${ }^{15}$

This study reviewed midterm outcomes of patients who had both mitral regurgitation and TR, who underwent MV repair with a rigid complete annuloplasty ring, and who simultaneously underwent TV repair using a simple strategy of identical sized TV annuloplasty ring.

\section{PATIENTS AND METHODS \\ Patients}

From April 2007 to January 2012, all patients with congestive heart failure at the University of Michigan Medical Center undergoing MV and TV repair using identical sized annuloplasty rings (either 26 or 28 $\mathrm{mm}$ ) were identified. Patients with endocarditis, rheumatic valve disease, or organic disease of the TV leaflets, including congenital anomalies, were excluded. Patient demographics, clinical characteristics, echocardiograms, operative reports, hospital records, and clinic notes were collected from the prospective University of Michigan Cardiovascular Databank, and a retrospective analysis was performed. Institutional review board approval was obtained for this study.

\footnotetext{
Methods

Annuloplasty ring type was determined by surgeon preference at the time of operation. In general, complete rigid rings were used in the mitral position. The TV ring size was matched to the MV annuloplasty ring size. Tricuspid rings were all rigid remodeling rings.

When we were collecting data from echocardiogram reports, descriptors such as "mild to moderate" or "moderate to severe" were recorded in our database as the greater of the 2 values (ie, "mild to moderate mitral regurgitation" was recorded as moderate). In cases in which echocardiogram
}

reports documented regurgitation as "none," " $1+,, "$ " $2+,$, " $3+$, , or " $4+$," these were reported as "none," "trace," "mild," "moderate," or "severe" in our database, respectively.

Descriptive statistics were used to describe the study population. Tricuspid gradient is reported as mean \pm standard error of means. Decline in RV function over time was evaluated for patients who had preoperative and 4-week postoperative echocardiograms available that specifically reported on RV function. A 70\% confidence interval (CI) for the proportion of patients with increased RV dysfunction 4 weeks postoperatively was calculated.

\section{RESULTS}

Fifty-three patients underwent combined MV and TV repair using identical sized rings between April 2007 and January 2012. Patient characteristics are summarized in Table 1 . The mean age was $65 \pm 1.7$ years and $43 \%$ were male. Preoperative New York Heart Association functional class was III or IV in $81 \%(n=43)$ and mean left ventricular ejection fraction was $33 \% \pm 2.2 \%$. All patients had moderate or greater mitral regurgitation before surgery. All patients also had preoperative moderate or severe TR or a preoperative tricuspid annulus diameter greater than 40 $\mathrm{mm}$. Concomitant procedures included coronary artery bypass grafting $(n=5)$, the maze procedure $(n=24)$, the Acorn procedure $(n=2)$, and atrial septal defect/patent foramen ovale closure $(n=7)$. Sixteen were reoperations. The average cardiopulmonary bypass and crossclamp times were $90 \pm 2.2$ minutes and $71 \pm 2.6$ minutes, respectively.

Four-week follow-up data were available for $48(91 \%)$ patients and intermediate-term data were available in $9(17 \%)$. There was no 30 -day mortality. There were 3 patients who required prolonged ventilatory support, 1 stroke, and 4 late deaths. Preoperative and postoperative TR, TV gradient, and RV function are reported in Table 2. The mean immediate postoperative TV gradient was $1.75 \pm 0.12 \mathrm{~mm} \mathrm{Hg}$ and at 4 weeks' follow-up it was $2.3 \pm 0.18 \mathrm{~mm} \mathrm{Hg}$. Four weeks postoperatively, $88 \%$ (42/48) of patients had TR considered to be mild or less on a scale of "none," "trace," "mild," "moderate," or "severe." At 4 weeks, $10 \%(5 / 48)$ had moderate TR (compared with $36 \%$ preoperatively) and $2 \%(1 / 48)$ had severe TR (compared with $34 \%$ preoperatively). RV function was specifically evaluated by echocardiography preoperatively and 4 weeks postoperatively in 30 patients. A 70\% CI was calculated around the percentage of patients whose $\mathrm{RV}$ function worsened during this time frame. Of the 30 patients, 30\% showed worsening of their RV function (CI 70\%, 21, 41). In addition, 33\% (CI 70\%, 24, 44) showed improvement in their RV function at the time of 4-week postoperative echocardiogram. No patient had any clinical evidence of RV failure at 4 weeks of follow-up.

\section{DISCUSSION}

Surgery of the TV for significant TR should occur at the time of MV surgery. Most now agree that surgical treatment 
TABLE 1. Patient characteristics

\begin{tabular}{|c|c|}
\hline Characteristic & Value $(\%), \mathbf{n}=\mathbf{5 3}$ \\
\hline Age at operation, $y$ & $65(41-88)$ \\
\hline Male $(\%)$ & $23(43)$ \\
\hline Preoperative smoking (\%) & $12(23)$ \\
\hline \multicolumn{2}{|l|}{ Preoperative comorbidity } \\
\hline COPD & $6(11)$ \\
\hline Renal failure & $8(15)$ \\
\hline Creatinine & $1.4 \pm 0.17$ \\
\hline Diabetes & $16(30)$ \\
\hline TIA & $4(7.5)$ \\
\hline CVA & $2(3.8)$ \\
\hline Preoperative EF & $33 \pm 2.2$ \\
\hline \multicolumn{2}{|l|}{ NYHA class $(\%)$} \\
\hline I & $0(0)$ \\
\hline II & $10(18.9)$ \\
\hline III & $39(73.6)$ \\
\hline IV & $4(7.5)$ \\
\hline Redo operation (\%) & $16(30)$ \\
\hline \multicolumn{2}{|l|}{ Concurrent procedures $(\%)$} \\
\hline Maze & $24(45)$ \\
\hline CABG & $5(9.4)$ \\
\hline Acorn & $2(3.8)$ \\
\hline $\mathrm{PFO} / \mathrm{ASD}$ closure & $7(13)$ \\
\hline \multicolumn{2}{|c|}{ Mitral/tricuspid ring size used (mm) } \\
\hline $26(\%)$ & $45(85)$ \\
\hline $28(\%)$ & $8(15)$ \\
\hline
\end{tabular}

of the MV alone does not necessarily result in improvement in RV function or secondary amelioration of TR. Further, reoperation for TV repair, if offered at all, carries high surgical risk.

Benedetto and colleagues ${ }^{2}$ showed significant reverse RV remodeling among patients treated with concomitant MV

TABLE 2. Changes in RV function, TR, and TV gradient over time

\begin{tabular}{|c|c|c|c|}
\hline Variable & Baseline & $\begin{array}{l}\text { Four-week } \\
\text { follow-up }\end{array}$ & $\begin{array}{c}\text { Intermediate-term } \\
\text { follow-up } \\
\text { (mean, 12.9 mo; } \\
\text { range, } 2-33 \mathrm{mo} \text { ) }\end{array}$ \\
\hline RV dysfunction & $\mathrm{n}=53(\%)$ & $\mathrm{n}=40(\%)$ & $\mathrm{n}=7(\%)$ \\
\hline None & $36(68)$ & $18(45)$ & $2(28.6)$ \\
\hline Mild & $8(15)$ & $9(23)$ & $1(14.3)$ \\
\hline Moderate & $4(8)$ & $8(20)$ & $2(28.6)$ \\
\hline Severe & $5(9)$ & $4(10)$ & $2(28.6)$ \\
\hline TR & $\mathrm{n}=53(\%)$ & $\mathrm{n}=48(\%)$ & $\mathrm{n}=9(\%)$ \\
\hline Mild or better & $16(30)$ & $42(88)$ & $8(89)$ \\
\hline Moderate & $19(36)$ & $5(10)$ & $0(0)$ \\
\hline Severe & $18(34)$ & $1(2)$ & $1(11)$ \\
\hline \multirow[t]{2}{*}{ TV gradient } & $\begin{array}{l}\text { Immediately } \\
\text { postop; } \mathrm{n}=53\end{array}$ & $\mathrm{n}=43$ & $\mathrm{n}=5$ \\
\hline & $1.75 \pm 0.12$ & $2.3 \pm 0.18$ & $2.8 \pm 0.74$ \\
\hline
\end{tabular}

$R V$, Right ventricle; $T R$, tricuspid regurgitation; $T V$, tricuspid valve.
repair/TV repair. They also demonstrated a significantly lower grade of TR and a significant improvement in functional class among the patients who underwent TV repair at the time of MV repair at 1 year's follow-up.

Any patient with greater than $2+$ TR or a tricuspid annular diameter $40 \mathrm{~mm}$ or greater in any echocardiographic view should be considered for TV repair. ${ }^{16}$ The best time to evaluate for TR is during a preoperative workup, before the patient reaches the operating room for the concomitant procedure. Under general anesthesia, even severe TR may appear mild. The TV annulus should also be measured during the preoperative echocardiogram along with RA and RV size and function.

The primary goal in surgical correction of functional TR is to reduce the annular size to achieve leaflet coaptation. The application of a rigid ring has been shown to offer the most durability over time in multiple series compared with flexible bands or plication annuloplasty techniques. ${ }^{8}$ Rigid annuloplasty should be the preferred surgical approach for significant TR if the leaflets are spared from the disease process.

\section{Ring Sizing in Functional TR}

Tricuspid sizing based on the septal leaflet is now believed to be an inaccurate method to determine tricuspid annular size in functional TR. The tricuspid annulus is dynamic and may change by as much as $19 \%$ in circumference during systole with a 30\% reduction in annular area. ${ }^{17,18}$ Fukuda and colleagues ${ }^{18}$ have demonstrated that the normal 3-dimensional annulus becomes more planar in patients with functional TR.

Further apprehension exists regarding size selection for the tricuspid annuloplasty because of the suggestion that undersizing the TV annuloplasty may result in subsequent TS. $\mathrm{We}^{1}$ have previously reported that tricuspid annuloplasty with an undersized ( 26 or $28 \mathrm{~mm}$ ) ring does not result in TS. Our results in this study support that conclusion and showed a peak gradient of $2.8 \pm 0.74$ at intermediate-term follow-up.

Other authors have warned against aggressively treating TR for fear of worsening RV function. ${ }^{13}$ In our study there was no significant worsening of RV function, with most patients having normal to only moderately decreased function at 4 weeks, in line with their preoperative right heart function. Further, no significant recurrent TR was seen at 4 weeks' follow-up with this approach.

\section{CONCLUSIONS}

We reviewed patients who underwent MV repair with a rigid complete annuloplasty ring and who simultaneously underwent TV repair with use of the identical sized TV annuloplasty ring (26 or $28 \mathrm{~mm}$ ). Our data suggest that an identical sized ring strategy can be used for TV repair as was used for MV repair, without 
development of TS or negative effects on right heart function. Further, this approach seems to prevent early recurrence of significant TR.

Despite the American College of Cardiology/American Heart Association and European Society of Cardiology guidelines, which support surgical repair of TR at the time of MV surgery in many patients, TV repair is underused. The current surgical volume of TV repair with or without concomitant MV surgery as quantified in the Society of Thoracic Surgeons National Cardiac Database averages between 4000 and 4500 operations per year (2005-2007). ${ }^{1}$ This represents only approximately one tenth of the greater than 50,000 MV operations performed yearly in the United States. ${ }^{19}$

Given the adverse consequences of allowing TR to progress in severity (such as worsening symptoms of right heart failure), it is logical that earlier intervention for TR, especially in the presence of right atrial and RV enlargement, would be beneficial. There are few data that can be used to specifically address this important question. A randomized trial comparing benign neglect of TR versus earlier intervention may be required to gain further insight and is presently being entertained by the National Heart, Lung, and Blood Institute.

Functional TR can be reliably repaired, much like functional mitral regurgitation, using an undersized annuloplasty ring. Using the identical sized rigid annuloplasty ring for concomitant MV repair/TV repair offers a relatively simple, safe, and effective strategy for treatment of functional mitral regurgitation and TR. The technique we describe is a simple and reliable method that provides effective and reproducible results. Longer follow-up and larger sample size are needed to evaluate the stability of these early results.

\section{References}

1. Rogers JH, Bolling SF. The tricuspid valve: current perspective and evolving management of tricuspid regurgitation. Circulation. 2009;119:2718-25.

2. Benedetto U, Melina G, Angeloni E, Refice S, Roscitano A, Comito C, et al. Prophylactic tricuspid annuloplasty in patients with dilated tricuspid annulus undergoing mitral valve surgery. J Thorac Cardiovasc Surg. 2012;143:632-8.

3. Agarwal S, Tuzcu EM, Rodriguez ER, Tan CD, Rodriguez LL, Kapadia SR. Interventional cardiology perspective of functional tricuspid regurgitation. Circ Cardiovasc Interv. 2009;2:565-73.
4. Cohn LH. Tricuspid regurgitation secondary to mitral valve disease: when and how to repair. J Card Surg. 1994;9:237-41.

5. Nath J, Foster E, Heidenreich PA. Impact of tricuspid regurgitation on long-term survival. J Am Coll Cardiol. 2004;43:405-9.

6. Bernal JM, Morales D, Revuelta C, Llorca J, Gutierrez-Morlote J, Revuelta JM. Reoperations after tricuspid valve repair. J Thorac Cardiovasc Surg. 2005;130: 498-503.

7. Singh SK, Tang GH, Maganti MD, Armstrong S, Williams WG, David TE, et al. Midterm outcomes of tricuspid valve repair versus replacement for organic tricuspid disease. Ann Thorac Surg. 2006;82:1735-41; discussion 1741.

8. McCarthy PM, Bhudia SK, Rajeswaran J, Hoercher KJ, Lytle BW, Cosgrove DM, et al. Tricuspid valve repair: durability and risk factors for failure. J Thorac Cardiovasc Surg. 2004;127:674-85.

9. Dreyfus GD, Corbi PJ, Chan KM, Bahrami T. Secondary tricuspid regurgitation or dilatation: which should be the criteria for surgical repair? Ann Thorac Surg. 2005;79:127-32.

10. Bonow RO, Carabello BA, Kanu C, de Leon AC Jr, Faxon DP, Freed MD, et al. ACC/AHA 2006 guidelines for the management of patients with valvular heart disease: a report of the American College of Cardiology/American Heart Association Task Force on Practice Guidelines (writing committee to revise the 1998 Guidelines for the Management of Patients With Valvular Heart Disease): developed in collaboration with the Society of Cardiovascular Anesthesiologists: endorsed by the Society for Cardiovascular Angiography and Interventions and the Society of Thoracic Surgeons. Circulation. 2006; 114:e84-231.

11. Vahanian A, Baumgartner H, Bax J, Butchart E, Dion R, Filippatos G, et al. Guidelines on the management of valvular heart disease: The Task Force on the Management of Valvular Heart Disease of the European Society of Cardiology. Eur Heart J. 2007;28:230-68.

12. Rivera R, Duran E, Ajuria M. Carpentier's flexible ring versus De Vega's annuloplasty; a prospective randomized study. J Thorac Cardiovasc Surg. 1985;89:196-203.

13. Tang GH, David TE, Singh SK, Maganti MD, Armstrong S, Borger MA. Tricuspid valve repair with an annuloplasty ring results in improved long-term outcomes. Circulation. 2006;114:I577-81.

14. Navia JL, Nowicki ER, Blackstone EH, Brozzi NA, Nento DE, Atik FA, et al. Surgical management of secondary tricuspid valve regurgitation: annulus, commissure, or leaflet procedure? J Thorac Cardiovasc Surg. 2010;139: 1473-82. e1475.

15. Antoniali F, Braile DM, Poterio GM, Ribeiro GC, Costa CE, Lopes MM. Tricuspid valve repair using the proportion between segments of normal tricuspid annulus as a parameter for annuloplasty. Rev Bras Cir Cardiovasc. 2007;22: 393-9.

16. Rogers JH, Bolling SF. Valve repair for functional tricuspid valve regurgitation: anatomical and surgical considerations. Semin Thorac Cardiovasc Surg. 2010; 22:84-9.

17. Tei C, Pilgrim JP, Shah PM, Ormiston JA, Wong M. The tricuspid valve annulus: study of size and motion in normal subjects and in patients with tricuspid regurgitation. Circulation. 1982;66:665-71.

18. Fukuda S, Saracino G, Matsumura Y, Daimon M, Tran H, Greenberg NL, et al. Three-dimensional geometry of the tricuspid annulus in healthy subjects and in patients with functional tricuspid regurgitation: a real-time, 3-dimensional echocardiographic study. Circulation. 2006;114(1 Suppl):I492-8.

19. Gammie JS, O'Brien SM, Griffith BP, Ferguson TB, Peterson ED. Influence of hospital procedural volume on care process and mortality for patients undergoing elective surgery for mitral regurgitation. Circulation. 2007;115:881-7. 